\title{
Noções introdutórias de direito ambiental
}

\author{
Eduardo Fernandes Bueno ${ }^{1}$ \\ Fábio André Testa ${ }^{2}$
}

\begin{abstract}
Resumo
Este trabalho tem o intuito de fornecer uma descrição retrospectiva de fatos relacionados ao M eio Ambiente. Há a inclusão dos principais aspectos históricos e, também, mencionar-se-á algumas catástrofes ocorridas ao meio ambiente. É mister, ainda, apresentar algumas conceituações importantes sobre 0 assunto, porque é perceptível que a falta de informação é um dos motivos que condiciona 0 conformismo em relação aos problemas ambientais. Não se pode olvidar de comentar alguns dos mais importantes princípios que tutelam as questões ambientais.
\end{abstract}

Palavras-chave: Direito; Meio-ambiente; Princípios e Desenvolvimento Sustentável.

\section{Introdução}

Desde tempos remotos o ser humano agride a natureza, com maior ou menor intensidade, alterando o meio em que vive; porém, faz isso buscando sua sobrevida, porque busca alimentos, matérias-prima, água etc. Desta feita, é perceptível que o homem via-se alheio à natureza, não era partícipe do meio natural, estava acima ou além deste. Não havia preocupação em preservar os recursos naturais, que eram considerados ilimitados e inesgotáveis.

Em grande parte a moral teocêntrica, depois de Cristo, influenciou nessa concepção ilusória de não-escassez até os idos do séc. XVI, porquanto se pensava que a natureza fora feita por Deus para os seus descendentes diretos, a saber, o homem e, conseqüentemente, se começasse a diminuir e escassear alimentos ou água, por exemplo, poder-se-ia esperar por milagres do divino. Posteriormente adveio a perspectiva antropocêntrica, embasada pela ciência e pela experimentação, cuja idéia fulcral era a de que o homem detinha o poder sobre a natureza, podendo, assim, alterá-la ao seu interesse e rigor. Isso aconteceu

\footnotetext{
${ }^{1}$ Acadêmico de Direito pela Universidade Estadual de Londrina.

${ }^{2}$ Graduado em Farmácia pela Universidade Estadual de Londrina em 1991. Graduado em Letras pela Universidade Estadual de Londrina em 2005. Acadêmico de Direito pela Universidade Estadual de Londrina.
} 
paulatinamente até 0 séc. XIX. Essas teses podem ser descritas com exímio pelo Excelentíssimo Juiz de Direito do Paraná, José Ricardo Alvarez Vianna, onde: "É certo que o Direito sempre se pautou por uma visão antropocêntrica na concepção das normas jurídicas fruto das raízes judaico-cristãs que a inspiraram" (VIANNA, 2004, p. 25).

Outrossim, com a Revolução Industrial, o meio social, cultural e natural sofreram e continuam sofrendo mudanças significativas. Contudo, esta perspectiva encontra uma grande problemática no século XXI, qual seja: A QUESTÃO AMBIENTAL, onde percebe se a escassez de fato de recursos naturais, como falta de alimentos, carência de energia motriz, escassez de água potável etc.

Não se tem o empreendimento de excluir ou pôr de fora a ação antrópica em relação ao meio ambiente, isso é inconcebível, tendo em vista que a Ciência do Direito Ambiental é de criação do homem, ou seja, como outras ciências, é cultura; então, o direito esta para servir ao gênero humano, solucionando e dirimindo problemas de ordem econômica, social, medicinal etc., em suma, para sobrevivência da espécie humana. Logo, o ser humano esta no centro das relações entre os humanos e destes com o meio em que vive ('biocentrismo'). ${ }^{3}$

0 pretendido neste trabalho é demonstrar que o tema é de extrema importância e que se deve dar relevância ao fato de que o descaso em relação ao meio ambiente acarretou e ainda continua acarretando em danos e alterações ambientais, na maioria das vezes irreversíveis e/ou irreparáveis, em especial, sobre o clima e vegetação. Sem falar que cientistas atestam que esses danos são realmente causados em grande parte por ação antropogênica. 0 ser humano e os demais seres do planeta sentem estes efeitos, experimentam certo desconforto, porque é perceptível o aumento na temperatura e alterações climáticas, a escassez de alimentos, catástrofes naturais etc., obrigando-se a repensar as desmedidas atitudes humanas e, assim, impulsionando a todos a criar meios de frear o dano ambiental. É mister a preservação ambiental, isso em consonância com 0 art. 225 da Carta Maior (...) "impondo-se ao Poder Público e à coletividade o dever de defendêlo e preservá-lo para as presentes e futuras gerações" e, ainda, com a Lei da Política Nacional do M eio Ambiente, lei n. 6.938/81, que influenciou e orientou a Carta M aior de 1988.

\footnotetext{
${ }^{3} 0$ termo 'BIOCENTRISMO' pode ser contatado da Declaração do Rio de Janeiro sobre o M eio Ambiente e Desenvolvimento (1992): PRINCÍPIO 1 - Os seres humanos estão no centro das preocupações com 0 desenvolvimento sustentável. Têm direito a uma vida saudável e produtiva, em harmonia com a natureza.
} 
Este preceito fundamental e esta lei são algumas das várias que norteiam e delimitam as ações humanas e desses com o meio ambiente, buscando preservar/conservar ou, ao menos, objetiva-se o desenvolvimento sustentável, ou seja, explorar a natureza de forma racional e degradar o menos possível o meio ambiente.

Desde o início do século passado (séc. XX), houve a criação da Liga das Nações Unidas, em 1919; perpassando pela criação da Organização das Nações Unidas, em 1945; da Conferência de Estocolmo, em 1972; Relatório Brundtland, 1987; do Rio +20 ou Eco 92; Protocolo de Kyoto, em 1999, entre outros, onde países desenvolvidos e em desenvolvimento realizaram reuniões e acordos com intuito de discutir os problemas decorrentes do desenvolvimento descontrolado dos mecanismos industriais causadores da poluição, com objetivo de solucionar, ou ao menos diminuir os impactos ambientais causados pelo homem ao meio ambiente. 0 desenvolvimento sustentável passa a ser objeto fundamental como forma de auxiliar a manutenção ambiental.

Desta feita, o presente trabalho busca discutir temas relevantes à preservação do meio ambiente, em especial a alguns princípios jurídicos e acordos transnacionais de Direito eminentemente Ambiental, tais como: 0 artigo 225, caput da Constituição Federal que diz “Todos têm direito ao meio ambiente ecologicamente equilibrado, bem de uso comum do povo e essencial à sadia qualidade de vida"[... $]^{4}$; princípio do direito humano fundamental; princípio da prevenção/precaução; princípio do poluidor/pagador e princípio do desenvolvimento sustentável.

O segundo capítulo abordará o conceito de meio ambiente e algumas catástrofes históricas. Estas influenciaram, em muito, a mudança do paradigma utilitarista para uma visão holística e global acerca da temática ambiental.

Ter-se-á no terceiro capítulo citações de alguns tratados e acordos internacionais que buscam a preservação do meio ambiente, com destaque para a Conferência de Estocolmo e a Conferência das Nações Unidas sobre o Meio Ambiente e Desenvolvimento (CNUMAD), comumente denominada Eco 92, considerada a fomentadora do Protocolo de Kyoto.

O quarto capítulo tratará sobre o direito ambiental e seus principais princípios na tutela ambiental, tais como o princípio do direito humano fundamental, princípio da

\footnotetext{
${ }^{4}$ Art. 225 da Constituição Federal de 1988.
} 
prevenção/precaução, princípio do poluidor/pagador e o princípio do desenvolvimento sustentável.

Por fim, o último capítulo demonstrará que apesar de incipiente, o Direito Ambiental tem apresentado alguns resultados positivos no que concerne ao tema do meio ambiente sustentável e equilibrado para as presentes e as futuras gerações. Vericar-se-á, ainda, que as sociedades estão mais sensíveis aos acontecimentos e alterações climáticas, onde o Direito Ambiental tem ajudado, em muito, a nortear os seres humanos a procurarem por meios eficazes de se viver com saúde e bem-estar social sem ter que necessariamente degradar e/ou poluir todo o meio ambiente e, também, sem ter que ser adotadas medidas de frear a economia dos países em desenvolvimento; o que se quer é um desenvolvimento sustentável. Urge, pois, uma visão 'biocêntrica' e 'ecocêntrica' para um Direito Ambiental, isto é: "Uma visão que tenha por escopo a preservação da vida em todas as suas formas, de modo a assegurar a existência da espécie humana", assim como dos demais seres vivos, assim ensina Vianna (VIANNA, 2004, p.25).

\section{Meio ambiente}

De acordo com a Lei da Política Nacional do M eio Ambiente, lei n. 6.938/81, em seu artigo 3o, inciso I, conceitua:

Art 3o - Para os fins previstos nesta Lei, entende-se por: I - meio ambiente, 0 conjunto de condições, leis, influências e interações de ordem física, química e biológica, que permite, abriga e rege a vida em todas as suas formas.

0 artigo mencionado é explicativo, portanto, o meio ambiente é a condição propícia e favorável a manutenção da vida em todas as suas formas. Ainda, disposto no Art. 2o, da lei supracitada, "A Política Nacional do Meio Ambiente tem por objetivo a preservação, melhoria e recuperação da qualidade ambiental propícia à vida, visando assegurar, no País, condições ao desenvolvimento sócio-econômico, aos interesses da segurança nacional e à proteção da dignidade da vida humana...".

Essa lei infraconstitucional foi recepcionada, de forma sistemática, pela Constituição Federal de 1988, porque é possível ver expressamente e implicitamente alguns termos disposto nos artigos da Carta Magna, vale elucidar a conformidade dos artigos acima 
mencionados, da lei n. 6.938/81 que se coadunam com o Art. 225 da C.F.: "Todos têm direito ao meio ambiente ecologicamente equilibrado, bem de uso comum do povo e essencial à sadia qualidade de vida". Percebe-se, portanto, termos sinônimos ao artigo da Carta Suprema à lei, como 'propício à vida' e 'essencial à sadia qualidade de vida'. Ainda, como ensina o llustríssimo Prof. José Afonso da Silva: "A primeira referência expressa ao meio ambiente ou a recursos ambientais na Constituição vem logo no art. 5ํ, LXXIII, que confere legitimação a qualquer cidadão para propor ação popular que vise a anular ato lesivo ao meio ambiente e ao patrimônio histórico e cultural" (DA SILVA, 2004, p.47).

Continua 0 i. Professor a citar os artigos que explicitam na, Constituição Federal do Brasil de 1988, referências ao meio ambiente são, pois, os artigos: 20, II; 23; 24, VI, VII e VIII; 91, §1으, III; 129, III; 170, VI; 173, §50; 174, §3ㅇ; 186, II; 200, VIII; 216, V; 220, §3ㅇ, II e o mais comentado neste trabalho que é 0 art. 225. Algumas referências implícitas contidas na Carta Magna de 1988: artigos 21, XIX, XX, XIII, XIV e (XXV conjugado com 0 art. 174, §3ㅇ); art. 22, IV, XII, XXVI; art. 23, II, III e IV; art. 24, VII conjugados aos arts. 215 e 216, entre outros ${ }^{5}$.

0 que se percebe com o que foi citado acima, é que de fato, principalmente no Brasil, existem princípios, leis, normas etc. no ordenamento jurídico que estão para tutelar e proteger o MEIO AM BIENTE, compreendido neste o meio ambiente natural ${ }^{6}$, meio ambiente artificial ${ }^{7}$, meio ambiente cultural ${ }^{8}$ e o meio ambiente do trabalho ${ }^{9}$. 0 que seria ideal é de

\footnotetext{
${ }^{5}$ Vide a Constituição Federal da República Federativa do Brasil de 1988.

${ }^{6}$ Meio Ambiente Natural: Art. 225, § 1으, inciso I - preservar e restaurar os processos ecológicos essenciais e prover o manejo ecológico das espécies e ecossistemas; inciso III - definir, em todas as unidades da Federação, espaços territoriais e seus componentes a serem especialmente protegidos, sendo a alteração e a supressão permitidas somente através de lei, vedada qualquer utilização que comprometa a integridade dos atributos que justifiquem sua proteção'e inciso VII - 'proteger a fauna e a flora, vedadas, na forma da lei, as práticas que coloquem em risco sua função ecológica, provoquem a extinção de espécies ou submetam os animais a crueldade. - Constituição Federal de 1988.

${ }^{7}$ Meio Ambiente Artificial: Art. 182: A política de desenvolvimento urbano, executada pelo Poder Público municipal, conforme diretrizes gerais fixadas em lei, tem por objetivo ordenar o pleno desenvolvimento das funções sociais da cidade e garantir o bem-estar de seus habitantes; Art. 21, inciso XVIII - planejar e promover a defesa permanente contra as calamidades públicas, especialmente as secas e as inundações, inciso XX instituir diretrizes para o desenvolvimento urbano, inclusive habitação, saneamento básico e transportes urbanos e Art. 50, XXIII - a propriedade atenderá a sua função social. - Constituição Federal de 1988.

${ }^{8}$ M eio Ambiente Cultural: Art. 216, - Constituem patrimônio cultural brasileiro os bens de natureza material e imaterial, tomados individualmente ou em conjunto, portadores de referência à identidade, à ação, à memória dos diferentes grupos formadores da sociedade brasileira, nos quais se incluem: I - as formas de expressão; II - os modos de criar, fazer e viver; III - as criações científicas, artísticas e tecnológicas; IV - as obras, objetos, documentos, edificações e demais espaços destinados às manifestações artístico-culturais; $V$ os conjuntos urbanos e sítios de valor histórico, paisagístico, artístico, arqueológico, paleontológico, ecológico e científico. - Constituição Federal de 1988.
} 
que todos os humanos tivessem consciência da questão ambiental, porém isso não ocorre; então é mister que aplique-se os princípios/ normas /leis ora mencionados, visto que é um dever ser (deontologia), é regra de conduta, para que se imponha respeito e preservação do meio ambiente, porque de bom grado e voluntariamente o homem não mudará sua postura para com o meio em que vive, porque é mais fácil se tornar rico ilicitamente, precedido do desmatamento, leia-se exploração do meio ambiente em todas suas formas. Agravante, ainda, nesta sociedade de consumo, onde o ideal da maioria da população é enriquecer e consumir exacerbadamente, ter versus ser.

Infelizmente, com as concepções teo/antropocêntrica, como fora citado anteriormente na introdução, o meio ambiente era visto como fonte inesgotável de recursos naturais o que é falso e que tem sido comprovado no decorrer da história. Assim sendo, vale lembrar dos inúmeros conflitos que houve entre muitas sociedades, tendo em vista que 0 homem travou inúmeras guerras com seus semelhantes, a saber, com os estrangeiros, e com o meio em que habita, porque sempre está à procura de recursos naturais para suprir suas necessidades básicas de sobrevivência e, muitas vezes, desarrazoadamente, busca a satisfação de vontades supérfluas, acarretando em degradação e desgaste do patrimônio natural, artificial, cultural e do trabalho, em suma, do meio ambiente. São exemplos de conflitos: a Guerra do Paraguai versus Brasil no séc. XIX; a do Brasil versus Bolívia - "Guerra do Acre", entre muitas citações que caberiam.

Nessa linha de raciocínio, tem-se antagonismo, pois, que o meio ambiente possui características de uso de direito difuso, uma vez que se caracteriza pelo reconhecimento de valores sociais respeitantes não a uma coletividade determinada (como os direitos sociais que indicam os direitos coletivos), mas pertence a todos os seres humanos, ou seja, esses direitos coletivos buscam a satisfação de um número indeterminado de pessoas, cuja lesão tem uma extensão transindividual, tratando-se, então, de direito difuso - caracterizado, principalmente, por ser dotado de transindividualidade, indivisibilidade e titulares indeterminados e interligados por circunstâncias de fato, como escreve o excelentíssimo Professor-Doutor em Direito Ambiental Celso Antonio Pacheco Fiorillo, em sua obra Curso de Direito Ambiental Brasileiro (FIORILLO, 2008, p. 4-5), vale dizer: um direito de todos, como

\footnotetext{
${ }^{9}$ Meio Ambiente Do Trabalho: Art. 200 - Ao sistema único de saúde compete, além de outras atribuições, nos termos da lei: VIII - colaborar na proteção do meio ambiente, nele compreendido o do trabalho. Constituição Federal de 1988.
} 
preconiza 0 art. 225 da C.F./88: "Todos têm direito ao meio ambiente ecologicamente equilibrado, bem de uso comum do povo e essencial à sadia qualidade de vida...".

Atualmente, ainda, o meio ambiente vem sofrendo grandes desgastes com 0 desenvolvimento industrial, modelo de produção intensiva e extensiva; em que a busca pela lucratividade se sobrepõe à preservação ambiental; tornando se, portanto, a poluição insustentável para uma qualidade de vida humana adequada, outrossim, aos demais seres habitantes do globo. Desenvolvem-se catástrofes climáticas, danos ao meio ambiente e danos à saúde do homem e das demais formas de vida. Assim sendo, nas palavras dos professores doutores Barral e Assed Ferreira: conclui-se que a questão do "esgotamento dos recursos naturais, com enfoque no processo de entropia global, que pode ser definida como a tendência que o planeta tem de caminhar em direção a um contínuo processo de deterioração" (BARRAL; ASSAD apud ASSAD, 2006, p. 13).

Ainda, hodiernamente, tem se o período da globalização e de preocupações e discussões acerca da poluição em nível regional, local e global, que influenciam e causam conflitos ambientais entre Estados vizinhos, visto que é difícil manter a poluição e suas conseqüências nas regiões onde foram produzidas. Destarte, originam-se desacordos entre países. Incitam-se conflitos entre países limítrofes, há exemplo do Canadá que vem se desgastando com seu vizinho, os Estados Unidos da América na questão do 'cinturão da ferrugem' (rust belt, também chamado de cinturão da manufatura, em inglês manufactured belt - área nordeste situada aproximadamente entre as cidades de Chicago e Nova lorque, cuja economia é baseada precipuamente na indústria pesada de metais e manufatura desses - siderúrgicas) e que a poluição despejada nos EUA invade e degrada o território e meio ambiente do Canadá.

Não obstante isso, de ordinário, vale citar o acidente em 1967 com o petroleiro inglês Torrey Canyon e a usina nuclear de Chernobil, ocorrido no dia 26 de abril de 1986 (originalmente chamada Vlademir Lenin), na Ucrânia.

Conseqüentemente, todos os seres vivos do planeta azul têm sentido algumas das implicações das alterações climáticas, bem como os Estados Unidos da América (EUA) - em que o Furacão Katrina, em New Orleans, no dia 29 de agosto de 2005 ceifou milhares de vidas humanas, o que preocupou toda a população mundial. Apesar daquela tragédia, os EUA são um dos poucos países que não aderiram a alguns tratados internacionais, a saber, o 
Protocolo de Kyoto. Com isso percebe-se que quem paga pela qualidade de vida do país mais desenvolvido do mundo são os países em desenvolvimento, por exemplo, o Brasil e a Índia, onde esses "têm o dever de frearem suas economias ou 'internacionalizar suas matas"" neste caso, a Amazônia.

Há, afinal, neste século uma mudança, apesar de incipiente e mínima, de paradigma: do utilitarismo desmedido e egocentrismo de alguns Estados hegemônicos ao comprometimento para o desenvolvimento sustentável da maioria dos países, influenciando-os à adesão a tratados e acordos multilaterais, visto que o planeta poderá sucumbir. Visto isso, urge acordos entre Estados com a intenção de dirimir os problemas relativos as mais diversas áreas: econômicas, sociais, políticas e do meio ambiente. Eis que se tem a criação de um grande instituto do Direito: o Direito Internacional, também conhecido como Direito das Gentes. Os Estados soberanos buscam assinar tratados e acordos internacionais e transnacionais buscando, assim, a manutenção e a contínua paz interna e externa desses Estados, sem, contudo, elidir a soberania desses.

Vale dizer que o Direito Internacional está para 'praticar a tolerância e a viver em paz, uns com os outros, como bons vizinhos; a unir as nossas forças para manter a paz e a segurança internacionais; a garantir, pela aceitação de princípios e a instituição de métodos, que a força armada não será usada, a não ser no interesse comum e; a empregar mecanismos internacionais para promover o progresso econômico e social de todos os povos', esses são algumas finalidades dispostas no preâmbulo da Carta das Nações Unidas, resultado da Conferência das Nações Unidas sobre Organização Internacional, em 1945. Ressalta-se, em conformidade com o presente trabalho, que o que se almeja com esse "progresso econômico e social de todos os povos" é que seja, de fato, um progresso econômico-social sustentável.

Em item seguinte, 0 assunto tratado será sobre alguns acordos transnacionais acerca do desenvolvimento sustentável em âmbito mundial.

\section{Direito ambiental e os tratados internacionais}

A crescente preocupação do homem em tutelar as condições ambientais deu origem ao nascimento do Direito Ambiental, ramo recente da ciência do Direito, cuja "incumbência de preservação é do Poder Público e de toda coletividade"; sendo assim, 0 
meio ambiente é um direito difuso, sua peculiaridade está no fato de que é o destinatário e o tutor do meio ambiente os Estados e todos os cidadãos concomitantemente; ainda, o meio ambiente por ser um "bem difuso é insuscetível de apropriação, mas sim há a possibilidade de gerenciá-los" (FIORILLO, 2008, p.13), como bem evidenciou Fiorillo. Igualmente, o meio ambiente é de todos e é de ninguém, é, pois, o direito de terceira geração, que é assim explicado por Paulo Bonavides (BONAVIDES, 2001, p. 523):

Dotados de altíssimo teor de humanismo e universalidade, os direitos da terceira geração tendem a cristalizar-se neste fim de século enquanto direitos que não se destinam especificamente à proteção dos interesses de um indivíduo, de um grupo ou de um determinado Estado. Têm primeiro por destinatário o gênero humano, mesmo num momento expressivo de sua afirmação como valor supremo em termos de existencialidade correta. Os publicistas e os juristas já os enumeram com familiaridade, assinalando-lhe o caráter fascinante do coroamento de uma evolução de trezentos anos dos direitos fundamentais. Emergiram eles da reflexão sobre temas referentes ao desenvolvimento à paz, ao meio ambiente, à comunicação e ao patrimônio comum da humanidade.

A preocupação em tutelar o meio ambiente para preservá-lo, com a ajuda da Ciência do Direito, fez com que no ano de 1923, em Paris, vários especialistas, das mais diversas áreas das ciências e do saber humano, de diversos Estados, se reunissem em congressos, com destaque ao I Congresso Internacional para a Proteção da Natureza. Menciona, além disso, o ilustre Guido Fernando Silva Soares que "o ano de 1960 é considerado, por boa parte dos doutrinadores internacionais, como 0 ano do nascimento do Direito Internacional do meio ambiente" (SOARES, 2003, p.23), logo no período pós-guerra, marcado pela devastação do meio ambiente, que fez com que a preocupação acerca do meio ambiente viesse à tona, culminando em discussões e acordos internacionais.

Com a preocupação concernente ao assunto, muitos países aderiram a tratados, acordos e convenções internacionais. Um dos mais conhecidos e embasados nas tragédias supracitadas (capítulo 2 deste trabalho, pág. 9) é o caso do petroleiro Torrey Canyon e do acidente nuclear de Chernobyl. Foi a Conferência de Estocolmo, realizada de 5 a 16 de junho de 1972, que introduziu na agenda política internacional a dimensão e os problemas ambientais, sendo marco inicial daquelas convenções. Além disso, a Conferência de Estocolmo foi aprovada durante a Conferência das Nações Unidas sobre o M eio Ambiente Humano. 
Ainda, em 1980 há a publicação de um relatório sobre o meio ambiente, na cidade de Nova lorque, cujo titulo é "A Estratégia Mundial para a Conservação" elaborado, patrocinado e supervisionado pelo Programa das Nações Unidas para o Meio Ambiente (PNUMA), inserindo, de inédito, o termo "desenvolvimento sustentável".

No Brasil, em que pese o Direito Ambiental ser de formação recente, está incluso na Carta Magna (Constituição Federal de 1988, Título VIII, Da Ordem Social, Capítulo VI, Do M eio Ambiente, Artigo 225, §§ e incisos), e nisso andou bem o legislador, tendo em vista a relevância da questão ambiental. Mesmo assim, "o Brasil está sempre na vanguarda das discussões ambientais. Há muitos juristas e ambientalistas preocupados com o meio ambiente. Essa questão não é uma preocupação apenas de um país, mas do mundo" (SIRVINSKAS, 2005, p.22), como leciona o excelso Sirvinskas. Hoje, o Direito Ambiental é visto como um ramo autônomo da Ciência do Direito visto que possui normas, diplomas legais e princípios que the são próprios, porém essa autonomia não é estanque, vale dizer, o Direito Ambiental é interligado às outras áreas do Direito - civil, comercial, administrativo, privado, público, internacional etc., só há essa divisão por fim metodológico, porque ajuda a compreensão factual e jurídica sobre o assunto, afinal, não obstante isso, o direito é UNO. Consiste num sistema normativo. "Como tal, pode ser estudado por unidades estruturais que o compõem, sem perder de vista a totalidade de suas manifestações. Essas unidades estruturais ou dogmáticas do sistema jurídico constituem as divisões da ciência jurídica, comportando subdivisões" (DA SILVA, 2005, p.33).

Finalmente, segundo Toshio Mukai, que cita Michel Prieur - Professor especialista em Direito Ambiental da Universidade de Limoges, França -: "enfim, o Direito Ambiental seria um direito "horizontal" que cobre os diferentes ramos do Direito (privado, público e internacional), e um Direito de "interações", que tende a penetrar em todos os ramos do Direito para neles introduzir a idéia Ambiental.."(MUKAl, 2007, p.12). É interessante observar como diferentes pessoas, diferentes culturas, diferentes formas de apreender a realidade convergem a um ponto comum: preservação do meio ambiente, principalmente na seara da Ciência do Direito.

Neste diapasão, na seqüência, para confirmar o ponto de consonância e inquietação com os impactos ambientais, adveio a Conferência das Nações Unidas sobre o Meio 
Ambiente e Desenvolvimento (conhecida como Eco 92), ocorrida na cidade do Rio de Janeiro, entre os dias 3 a 14 de junho de 1992.

A Eco 92 conseguiu um marco histórico, envolvendo 179 países do mundo (de norte a sul, de leste a oeste) na discussão ambiental. Foi possuidora de acertada ideologia, a de se estabelecer metas de frear o desenvolvimento insustentável, ou seja, esse que degrada o meio ambiente sem se preocupar com os impactos ambientais, sociais e culturais. Dessa conferência resultou, então, na Agenda 21Global, que é o estabelecimento de que as autoridades de cada país implemente uma Agenda 21 Local, vale dizer, é a cooperação de todos os institutos sociais (sociedade civil, governos, organizações não-governamentais, empresas, etc.) para a consecução do desenvolvimento sustentável, dentro de um determinado Estado, para assim o mundo todo ter um desenvolvimento sustentável e adequado a vida em todas as suas formas para as presentes e futuras gerações.

Vale elencar as Ações Prioritárias da Agenda 21 Brasileira, que contém 21 objetivos, posto e ordenado em cinco blocos, quais sejam ${ }^{10}$ :

\section{Ações Prioritárias da Agenda 21 Brasileira - Plataforma das 21 ações prioritárias \\ Bloco I: A economia da poupança na sociedade do conhecimento}

Objetivo 1 - Produção e consumo sustentáveis contra a cultura do desperdício

Objetivo 2 - Ecoeficiência e responsabilidade social das empresas

Objetivo 3 - Retomada do planejamento estratégico, infra-estrutura e integração regional

Objetivo 4 - Energia renovável e a biomassa

Objetivo 5 - Informação e conhecimento para o desenvolvimento sustentável

\section{Bloco Il: Inclusão social para uma sociedade solidária}

Objetivo 6 - Educação permanente para o trabalho e a vida

Objetivo 7 - Promover a saúde e evitar a doença, democratizando o SUS

Objetivo 8 - Inclusão social e distribuição de renda

Objetivo 9 - Universalizar o saneamento ambiental protegendo o ambiente e a saúde

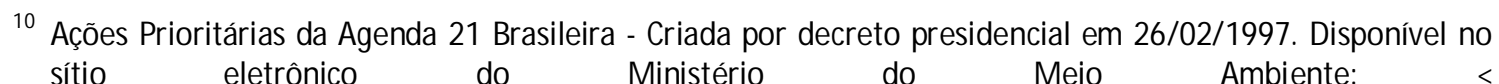
http://www.mma.gov.br/estruturas/agenda21/_arquivos/acoesprio.pdf >Acesso em: jul. 2008. 


\title{
Bloco III: Estratégia para a sustentabilidade urbana e rural
}

Objetivo 10 - Gestão do espaço urbano e a autoridade metropolitana

Objetivo 11 - Desenvolvimento sustentável do Brasil rural

Objetivo 12 - Promoção da agricultura sustentável

Objetivo 13 - Promover a Agenda 21 Local e o desenvolvimento integrado e sustentável

Objetivo 14 - Implantar o transporte de massa e a mobilidade sustentável

\section{Bloco IV: Recursos naturais estratégicos: água, biodiversidade e florestas}

Objetivo 15 - Preservar a quantidade e melhorar a qualidade da água nas bacias hidrográficas

Objetivo 16 - Política florestal, controle do desmatamento e corredores de biodiversidade

\section{Bloco V: Governança e ética para a promoção da sustentabilidade}

Objetivo 17 - Descentralização e o pacto federativo: parcerias, consórcios e o poder local

Objetivo 18 - Modernização do Estado: gestão ambiental e instrumentos econômicos

Objetivo 19 - Relações internacionais e governança global para o desenvolvimento sustentável

Objetivo 20 - Cultura cívica e novas identidades na sociedade da comunicação

Objetivo 21 - Pedagogia da sustentabilidade: ética e solidariedade

Como menciona o Presidente da República do Brasil, à época de seu mandato, Fernando Henrique Cardoso:

\begin{abstract}
0 maior desafio da Agenda 21 Brasileira é internalizar nas políticas públicas do país os valores e princípios do desenvolvimento sustentável. Esta é uma meta a ser atingida no mais breve prazo possível. A chave do sucesso da Agenda 21 Brasileira reside na responsabilidade, solidariedade e integração desenvolvidas por toda a sociedade ao longo de sua construção. 0 próximo desafio é implementá-la, para que o Brasil alcance novo padrão civilizatório em um contexto mundial de profundas transformações. ${ }^{11}$
\end{abstract}

${ }^{11}$ Fernando Henrique Cardoso - Presidente da República Federativa do Brasil, mandato de $1^{\circ}$ de janeiro de 1995 a 31 de dezembro de 2002. Disponível no sítio eletrônico do Ministério do M eio Ambiente. Acesso em jul 2008:<http://www.mma.gov.br/estruturas/agenda21/_arquivos/acoesprio.pdf > 
Assim, cada país estabeleceria qual seria sua Agenda 21Local, vale dizer, qual seriam as prioridades ambientais, para assim, apresentar princípios norteadores para a consecução de se por em prática o ideal que é o desenvolvimento sustentável, tendo em vista que deveria se considerar as diferentes situações sociais, econômicas e naturais dos países participantes, com fins à justiça social.

Do dia 26 de agosto a 04 de setembro de 2002, na cidade de Johannesburgo, na África do Sul, a Cúpula Mundial de Desenvolvimento Sustentável, conhecida como Rio + 10, reuniu-se para dar seguimento às discussões que começaram em 1972 em Estocolmo e em 1992 no Rio de Janeiro.

Então, muitas concepções filosóficas influenciaram o Direito Internacional Ambiental, assim também influenciaram, preponderantemente, o Direito Nacional, desta feita logo adveio a instituição da Política Nacional para o Meio Ambiente, como por exemplo, a Lei n. 6.938, de 31 de agosto de 1981 (mencionado no capítulo 2 'Meio Ambiente', pág. 6). Há, portanto, um grande avanço do Direito Ambiental no país. Conseqüentemente, como já fora mencionado, a Constituição Federal vigente recepciona e incorpora muitos princípios, normas etc. contidos naquela lei infraconstitucional.

Não obstante, os acordos e tratados internacionais engendravam bastantes discussões acirradas, porque o tema Meio Ambiente envolve fatores econômicos e políticos, principalmente, decorria, então, que Estados tinham dissidências no trato para com a questão ambiental. 0 principal ponto de discordância era 0 de que países desenvolvidos 'queriam desacelerar o desenvolvimento dos países em desenvolvimento', isto era um dos argumentos utilizados pelas nações que estavam com a economia 'em aquecimento'. Mas, com as evidências e as 'punições' que as populações mundiais têm enfrentado de ordem climática e atmosférica, entre outras, houve um maior esforço para se chegar a um consenso: - 0 Desenvolvimento Sustentável para as presentes e futuras gerações (intergeracionalidade) e bem-estar social, em nível mundial.

Por conseguinte e, em consonância com Sirvinskas, o direito de terceira geração, é a cooperação entre Estados autônomos e independentes que buscam a satisfação de um princípio final, qual seja, o desenvolvimento da paz, a preservação do meio ambiente e do 
patrimônio comum à humanidade, haja vista os encontros e acordos internacionais mencionados acima - em suma, fraternidade entre Países.

No próximo capítulo serão explanados alguns dos princípios norteadores do direito ambiental.

\section{Princípios de Direito Ambiental}

Em decorrência dos expostos acima, o Direito Ambiental tem se preocupado e se fundamentado em vários princípios para se permitir o desenvolvimento racional e ambientalmente equilibrado.

Ainda, citando renomados juristas, como Gomes Canotilho e M aurice Kanto:

[...] os princípios são normas jurídicas impositivas de uma optimização, compatíveis com vários graus de concretização, consoantes os condicionalismos fácticos e jurídicos. Permitem o balanceamento de valores e interesses (não obedecem, como as regras, à 'lógica de tudo ou nada'), consoante o seu peso e ponderação de outros princípios eventualmente conflitantes" (José Joaquim Gomes Canotilho, Direito Constitucional, Coimbra, Livraria Almedina, PP. 1,034-1.035) (CANOTILHO apud MACHADO, 2005, p.53).

Igualmente, "alguns princípios aqui expostos têm apoio em declarações internacionais, o que, como assevera Maurice Kanto, "cresce a potencialidade de seus princípios tornarem-se normas costumeiras, quando não se transformarem em normas jurídicas oriundas de convenções".("Lês nouveaux principes du Droit International de I'Environnement", Revue Juridique de I'Environnement 1/11-30, Limoges, SFDE, 1993) (KANTO apud M ACHADO, 2005, p. 53).

Citado isso, vale dizer que esses princípios estão para o nortear o Direito Internacional e o Direito Nacional Ambientais, como pode ser constatado na LEI № 6.938, de 31 de AGOSTO de 1981(supracitada, no capítulo 2 'M eio Ambiente', pág.5) conjugada ao DECRETO № 5.098, de 3 de JUNHO de $2004^{12}$ 2 brasileiras e, acima de tudo, 0 artigo 225, parágrafos e incisos da Constituição Federal de 1988 da República Federativa do Brasil.

\footnotetext{
${ }^{12}$ Art. 1o Fica criado o Plano Nacional de Prevenção, Preparação e Resposta Rápida a Emergências Ambientais com Produtos Químicos Perigosos - P2R2, com o objetivo de prevenir a ocorrência de acidentes com produtos químicos perigosos e aprimorar o sistema de preparação e resposta a emergências químicas no País.
} 
Sendo assim, consoante ao que certifica Leme Machado: "Os princípios aqui abordados estão formando e orientando a geração e a implementação do Direito Ambiental" (MACHADO, 2005, p. 53). Logo abaixo, explicar-se-á, de forma sintética, os princípios que são comumente elencados e tidos como os mais importantes. São, então: Princípio do Direito Humano Fundamental; Princípio da Prevenção e Precaução; Princípio do Poluidor/Pagador (PPP); e Princípio do Desenvolvimento Sustentável.

\section{Princípio do Direito Humano Fundamental}

O eminente Paulo de Bessa Antunes ensina que "o primeiro e mais importante princípio do Direito Ambiental é: o direito ao ambiente é um direito humano fundamental" (ANTUNES, 2005, p. 25) que está embasado pelo artigo 225 da Carta Magna de 1988, citado na introdução deste trabalho. Percebe-se o relevo dado ao tema pertinente ao meio ambiente, tendo em vista que o ser humano está no epicentro desse tema, ainda, há a citação do termo 'homem' e 'humano' nos itens 1, 2 e 3 da Declaração de Estocolmo, realizada entre os dia 05 e 16 de junho de 1972. Ou seja, como é o ser humano quem valora e, portanto, vem a se preocupar com o meio em que vive, compete, conseqüentemente, ao gênero humano as preocupações de ordem ambiental.

Ainda, este é o princípio mais relevante, porque o meio ambiente é direito de todos, ou seja, cabe a todos usufruir e preservar (direito e dever). Assim, o meio ambiente é o bem mais importante e que constitui a vida em todas as suas formas. Logo se percebe 0 porquê da relevância e distinção dado ao meio ambiente como direito humano fundamental.

\section{Princípio da prevenção e princípio da precaução}

O princípio da prevenção é o que deve nortear as condutas humanas, pois os impactos ambientais já são de conhecimento prévio, assim o ser humano deverá estar

\footnotetext{
Parágrafo único. O P2R2 será constituído de ações, atividades e projetos a serem formulados e executados de forma participativa e integrada pelos governos federal, distrital, estaduais e municipais e pela sociedade civil, e observará os princípios, diretrizes estratégicas e a organização definidos neste Decreto.

Art. 20 São princípios orientadores do P2R2, aqueles reconhecidos como princípios gerais do direito ambiental brasileiro, tais como: I - princípio da informação; II - princípio da participação; III - princípio da prevenção; IV - princípio da precaução; V - princípio da reparação; e VI - princípio do poluidor-pagador. Revista de Direito Público, Londrina, v, 4, n. 3, p.1-19, set./dez. 2009
} 
atento ao seu meio ambiente e não agir sem ampla e irrestrita avaliação das conseqüências. Ainda, como menciona i. Antunes, "o principio da prevenção aplica-se a impactos ambientais já conhecidos e dos quais se possa, com segurança, estabelecer um conjunto de nexos de causalidade que seja suficiente para a identificação dos impactos futuros prováveis" (ANTUNES, 2005, p. 35). Só para elucidar, o acidente ocorrido em Chernobil, sendo que o assunto sobre energia nuclear engendra inúmeras discussões e divergências, porquanto, tem se comprovado que determinadas ações humanas sem um razoável estudo prévio e sem constatar fatos históricos pode se insurgir em catástrofes, degradação, dano e poluição ao meio ambiente. Porém, "não há atividade humana que possa ser considerada isenta de riscos; o que a humanidade faz, em todas suas atividades, é uma análise de custo e benefício entre o grau de risco aceitável e o beneficio que advirá da atividade" (ANTUNES, 2005, p. 33).

Outrossim, em se tratando do princípio da prevenção, aduz Leme Machado: No Brasil, quando a Lei 6.938/81 diz, em seu art. 2ํㅜ , que em sua Política Nacional do Meio Ambiente observará como princípios a: "inc. IV - proteção de ecossistemas, com a preservação das áreas representativas", e "inc. IX - proteção de áreas ameaçadas de degradação", "está indicando especificamente onde aplicar-se o princípio da prevenção. Não seria possível proteger sem aplicar medidas de prevenção" (MACHADO, 2005, p. 82).

Entretanto, o princípio da precaução, também chamado de "prudência ou cautela", apesar de estar muito próximo daquele supracitado, não se confunde, porque não se tem a percepção concreta dos impactos que podem ocasionar, sendo que se tem uma perspectiva abstrata e não prática das conseqüências de determinadas ações humanas, visto que se se tivesse cientificamente comprovadas essas conseqüências não se trataria de precaução, mas sim, de prevenção. 0 princípio da precaução foi estabelecido na Eco 92 ou Declaração do Rio, estando tipificado como Princípio no 15, o qual dispõe:

Com o fim de proteger o meio ambiente, os Estados deverão aplicar amplamente 0 critério de precaução conforme suas capacidades. Quando houver perigo de dano grave ou irreversível, a falta de certeza científica absoluta não deverá ser utilizada como razão para se adiar a adoção de medidas eficazes em função dos custos para impedir a degradação do meio ambiente (CONFERÊNCIA DAS NAÇÕES UNIDAS apud MILARÉ, 2001, p.119). 
Ainda, consoante ao Princípio no 15, da Eco 92, que coaduna-se 0 artigo 21, inciso XXIII, alínea a, da Constituição Federal de 1988 : “Compete à União: XXIII - explorar os serviços e instalações nucleares de qualquer natureza e exercer monopólio estatal sobre a pesquisa, a lavra, o enriquecimento e reprocessamento, a industrialização e o comércio de minérios nucleares e seus derivados, atendidos os seguintes princípios e condições: a) toda atividade nuclear em território nacional somente será admitida para fins pacíficos e mediante aprovação do Congresso Nacional." (grifo nosso). Está, pois, expresso nesta alínea de que para se poder pesquisar, industrializar ou comercializar serviços e instalações nucleares, das quais poderão advir riscos imensuráveis, deverá se ter aprovação do Congresso Nacional. Vale dizer, se implicar risco em de dano ambiental em sentido amplo, o Congresso não autorizará a utilização de qualquer componente que gere danos ao meio ambiente. É, pois, visível que o legislador se anteviu e impôs norma para se precaver ou prevenir risco presumível, atual e iminente. Andou bem o legislador, afinal, o Estado é responsável por manter a sadia qualidade do meio ambiente e do ser humano (através de seus órgãos: União, estados federados, M unicípios e territórios).

Com isso temos que, de acordo com atitudes insensatas do passado e o medo de condutas humanas irracionais e imprudentes acerca do meio ambiente e que possam impactar e, até mesmo, levar o planeta à destruição futuramente devem ser deixados de levar a cabo sua execução, sob pena de aqueles que incorrerem em efetuar tal ato desmedido sofrer sanções legais, eis que se tem o princípio da prevenção/precaução.

Esses princípios foram colocados em mesmo tópico por mérito metodológico, haja vista que são bastante similares, buscando assim uma analogia e maior compreensão sobre os temas abordados, a saber, os princípios da prevenção e da precaução.

\section{Princípio do Poluidor/ Pagador (PPP)}

Como bem ensina o eminente jurista Leme Machado: "O uso dos recursos naturais pode ser gratuito como pode ser pago. A raridade do recurso, o uso poluidor e a necessidade de prevenir catástrofes, entre outras coisas, podem levar à cobrança do uso dos recursos naturais" (MACHADO, 2005, p. 59).

Tendo em vista que os recursos naturais são escassos e que a utilização por toda a população mundial causa a redução e degradação do meio ambiente, surge um princípio 
amparado pela legislação brasileira, não que os anteriores não o sejam, porém, este princípio além de aplicar sanções, implica penas pecuniárias, com a intenção de se fazer com que o poluidor (um ente particular ou público) busque fontes de degradar o menos possível o ambiente - em suma, objetiva-se o desenvolvimento sustentável, ou seja, não se quer que degrade o meio ambiente, preserve-o.

Em síntese, o princípio poluidor-pagador possui caráter preventivo e repressivo, buscando em primeiro lugar evitar o dano ambiental, que se acaso houver, deve ser reparado, sujeitando-se o poluidor às responsabilidades civil, administrativa e/ou criminal, decorrentes de seus atos. Nesse sentido, vale as palavras do Prof. Celso Antonio Pacheco Fiorillo: "Podemos verificar no princípio do poluidor-pagador duas órbitas de alcance: a) busca evitar a ocorrência de danos ambientais (caráter preventivo); e b)ocorrido o dano, visa sua reparação (caráter repressivo)" (FIORILLO, 2008, p. 37)

Em que pese esse caráter preventivo e repressivo de que o direito ambiental é dotado, 0 intento finalístico é de que não se degrade, não se cause dano e/ou não polua o meio ambiente, porque é impossível quando ocorrido o dano ao patrimônio ambiental voltar se ao status quo, vale dizer, voltar ao estado originário e natural do meio ambiente, assim, ocorre um dano irreparável e irreversível. É impossível recuperar completamente o dano causado ao meio ambiente por parte do agente, mas é necessária que se impeça a depredação deste patrimônio essencial e indispensável à vida, em todas suas formas.

Assim sendo, no âmbito jurídico, quando se impõe uma norma de conduta ou uma sanção moral, civil, administrativa e, até mesmo sanção penal, busca se uma proteção ao meio ambiente, através da responsabilidade civil por dano ecológico, responsabilidade essa que independe de culpa do agente, pois "se funda na idéia de que a pessoa que cria o risco deve reparar os danos advindos de seu empreendimento. Basta, portanto, a prova da ação ou da omissão do réu, do dano e da relação de causalidade" (GONÇALVES, 2003, p. 63). Busca-se, então, a prevenção e a preservação do meio ambiente.

Desta feita, o binômio poluidor/pagador tem uma característica de alta relevância, sendo que emprega a significação de: aquele que polui de forma insustentável deve pagar. Neste diapasão, quer-se que diminua ou cesse a poluição. Nunca pode ser o contrário, pagador/poluidor, senão aqueles que detêm e concentram um montante monetário elevado terão o direito de pagar para poluir. Ainda, como bem mencionou o Prof. Fiorillo: "Não traz 
como indicativo 'pagar para poder poluir', 'poluir mediante pagamento' ou 'pagar para evitar a contaminação'" (FIORILLO, 2008, p. 36).

Disso, poder-se-ia pensar que os países do Anexo I (países industrializados) e países do Anexo II (países desenvolvidos), da Convenção-Quadro das Nações Unidas sobre a Mudança do Clima (CQNUMC ou UNFCCC, traduzido do inglês: United Nations Framework Convention on Climate Ghange), poderiam pagar aos países do Não Anexo I (em desenvolvimento) para "limpar" a poluição atmosférica causada por aqueles países industrializados/desenvolvidos.

Nesta empreitada, pode-se até especular que os Mecanismos de Desenvolvimento Limpo (MDL) - mais popularmente conhecidos como créditos de carbono - possam ser vendidos a países desenvolvidos por países em desenvolvimento, para assim, os países desenvolvidos 'pagarem para poder poluir'. O que era para ser de caráter compensatório e de reversão aos danos ambientais, acaba permitindo que países como os EUA continuem devastando o planeta. Ou seja, o que se queria como princípio de poluidor/pagador torna-se 'princípio da permissão'.

Logo, se o dano ao meio ambiente for certo e atual, deve haver a reparação do dano, independentemente de culpa, porque o agente assumiu o risco de produzi-lo. Sendo assim, como leciona o Eminente Jurista Carlos Roberto Gonçalves:

A reparação do dano ambiental, como já afirmado, pode consistir na indenização dos prejuízos, reais ou legalmente presumidos, ou na restauração do que foi poluído, destruído ou degradado. A responsabilidade do réu pode ser repressiva de lesão consumada ou preventiva de sua consumação iminente (GONÇALVES, 2003, p. 71).

Deve-se, portanto, reprovar a conduta danosa, tida como delituosa, impondo normas de condutas preventivas ou repressivas se se presumir dano certo e propenso a acontecer ou decorrer da lei. Se isso não obstar a conduta e advier a lesão ao patrimônio ambiental, faz se mister sanções civis, administrativas e/ou penais ao agente, dependendo da intensidade do dano provocado. Por isso o título deste tópico de Princípio do Poluidor Pagador. 


\title{
Princípio do desenvolvimento sustentável
}

O desenvolvimento sustentável é uma das metas do século XXI. Desta feita, a Constituição Federal de 1988 abarca esta finalidade, é o que assevera o professor Daniel Rocha Corrêa:

\begin{abstract}
A Constituição do Brasil consagra o desenvolvimento como um dos objetivos da República e reconhece a necessidade de proteção ao meio ambiente, como princípio de Ordem Econômica. Nessa perspectiva, o ordenamento jurídico brasileiro valoriza as atividades produtivas que causem menores efeitos negativos ao meio ambiente e reconhece que a qualidade de ambiental é um dos modos para se garantir o equilíbrio ambiental (CORRÊA apud BARRAL; PIM ENTEL, 2006, p. 127).
\end{abstract}

Em consonância à busca pelo desenvolvimento e, com o que foi dito anteriormente, o termo desenvolvimento sustentável ganha alto relevo na Eco 92, a qual empregou o termo em onze de seus vinte e sete princípios. Nada mais justo que concordar com esse feito e declarar que o que se quer um é "meio ambiente ecologicamente equilibrado"; devemos todos ser partícipes da ideologia, tanto em âmbito local, nacional, regional e global. Sustentabilidade, como ensina Luís Paulo Sirvinskas, é:

Desenvolvimento ecologicamente equilibrado, desenvolvimento sustentado e ecodesenvolvimento - como sendo a conciliação de duas situações aparentemente antagônicas; de um lado, temos a necessidade da preservação do meio ambiente, e, de outro, a necessidade de incentivar o desenvolvimento socioeconômico. Essa conciliação será possível com a utilização racional dos recursos naturais, sem, contudo, causar poluição ao meio ambiente (SIRVINSKAS, 2005, p. 5-6).

Ainda, desenvolvimento sustentável "é o desenvolvimento capaz de suprir as necessidades da geração atual, sem comprometer a capacidade de atender as necessidades das futuras gerações. É o desenvolvimento que não esgota os recursos para o futuro". ${ }^{13}$ Assim o que se quer de fato e se preconiza nesse ideal é buscar a coexistência de forma harmônica entre economia e meio ambiente, para as presentes e as futuras gerações. Com

\footnotetext{
${ }^{13}$ Acesso em 13 de outubro de 2008 e disponível no endereço eletrônico da WWF: বtttp://www.wwf.org.br/informacoes/questoes_ambientais/desenvolvimento_sustentavel/index.cfm>
}

Revista de Direito Púbuco, LondRinA, V, 4, N. 3, P. 210-232, Set./ DeZ. 2009. 
advento de novas tecnologias isso é mais passível de se alcançar, na verdade isso é meta imprescindível.

Existem outros princípios, que, no entanto prolongarão demais a discussão, sendo que os mais expressivos, ao nosso entender, estão dispostos acima.

Por fim, falamos da importância que o Direito Ambiental tem tido nos últimos anos, tanto nacional quanto internacionalmente, e ademais a educação ambiental será edificante para se querer ter meios de se viver digna e humanamente, com harmonia nos meios natural, social, cultural e ambiental.

\section{Conclusão}

Não se pode mais postergar o cuidado com o meio ambiente; este planeta em que vivemos necessita de medidas e atitudes imediatas e eficazes no que tange à sua preservação. 0 primeiro passo seria a informação, todos nós precisamos deste conteúdo metalingüístico que diz respeito às definições técnico-científicas em relação ao meio que habitamos, ou seja, faz-se mister sabermos o que é o meio ambiente, qual sua importância para as gerações atuais e futuras e, que implicações poderão advir do uso indiscriminado de seus recursos naturais. As pesquisas acerca dos efeitos nefastos da destruição da natureza andam a passos rápidos, obrigando-nos a acordos e tratados em nível mundial, a fim de tentarmos resolver, ou ao menos mitigar, as graves conseqüências provenientes de nossa negligência total quanto às questões ambientais.

Pode-se afirmar que apesar dos iminentes riscos às espécies vivas de nosso planeta, as iniciativas nacionais e internacionais estão longe do que se considera ideal em termos de uma harmonização legislativa. Com relação aos princípios norteadores da tutela ambiental, há ainda um longo caminho para que eles possam embasar e harmonizar as questões jurídicas de maneira eficaz. Pode-se afirmar que são, até o presente momento, muito tímidas as iniciativas nacionais e internacionais com 0 intuito real de que se equacionem os problemas ligados às questões de preservação ambiental. Entretanto, não nos esqueçamos de que o maior empecilho é, de fato, o processo econômico e, aqui, fica a pergunta: como manter os patamares de crescimento econômico sem a deterioração da natureza?

Agora é torcer para que o seguinte raciocínio filosófico não se deteriore a tal ponto de virar apenas mais um clichê: "Somente quando o homem cortar a última árvore, poluir o 
último rio, e matar o último peixe é que ele se dará conta de que não se pode comer dinheiro".

\section{Referências}

AÇÕES PRIORITÁRIAS DA AGENDA 21 BRASILEIRA - Criada por decreto presidencial em 26/02/1997. Disponível em:

$\varangle t \mathrm{t}: / /$ www.mma.gov.br/estruturas/agenda21/_arquivos/acoesprio.pdf>Acesso em: jul. 2008.

ANTUNES, Paulo de Bessa. Direito ambiental. 8. ed. Rio de Janeiro: Lúmen Júris, 2005.

BARRAL, W elber; PIM ENTEL, Luiz Otávio (Org.). Direito Ambiental e Desenvolvimento. Florianópolis: Fundação Boiteux, 2006.

BRASIL, Constituição Federal (1988). Vade M ecum Saraiva/obra coletiva de autoria da Editora Saraiva com a colaboração de Antonio Luiz de Toledo Pinto, Márcia Cristina Vaz dos Santos Windt e Livia Céspedes. São Paulo: Saraiva, 2006.

M ACHADO, Paulo Affonso Leme. Direito Ambiental Brasileiro. 13. ed. São Paulo: Malheiros, 2005.

FIORILLO, Celso Antonio Pacheco. Curso de Direito Ambiental Brasileiro. 9. ed. São Paulo: Editora Saraiva, 2008.

GONÇALVES, Carlos Roberto. Comentários ao Código Civil - Parte Especial do Direito das Obrigações, São Paulo: Editora Saraiva, Volume 11, 2003.

M ACHADO, Paulo Affonso Leme. Direito Ambiental Brasileiro. 13. ed. São Paulo: M alheiros, 2005.

M ILARÉ, Edis. Direito do ambiente: doutrina, prática, jurisprudência, glossário. São Paulo: Revista dos Tribunais, 2001.

MUKAI, Tohio. Direito Ambiental Sistematizado. Rio de Janeiro: Editora Forense Universitária. 60 Edição. 2007.

SILVA, José Afonso da. Direito Ambiental Constitucional. 5. ed. São Paulo: Malheiros, 2004.

SILVA, José Afonso da. Curso de Direito Constitucional Positivo. 25. ed. São Paulo: Malheiros Editores, 2005.

SIRVINSKAS, Luís Paulo. Manual de direito ambiental. São Paulo: Saraiva, 2005. 
SOARES, Guido Fernando Silva. A proteção Internacional do M eio Ambiente. Barueri:

Manoele, 2003.

VIANNA, José Ricardo Alvarez. Responsabilidade Civil por Danos ao M eio Ambiente. Curitiba: Juruá, 2004. 